AKUNTABILITAS

Vol. VIII, No. 1, April 2015

P-ISSN: $1979-858 \mathrm{X}$

Halaman $01-17$

\title{
PRAKTIK AUDIT SYARIAH DI LEMBAGA KEUANGAN SYARIAH INDONESIA
}

\author{
Qonita Mardiyah \\ Sepky Mardian \\ Sekolah Tinggi Ekonomi Islam SEBI
}

\begin{abstract}
Islamic financial institutions (IFIs) have grown rapidly since the last few years. It raises the issue of shariah compliance in IFIs and the need for a new audit function, shariah audit. It's functions to ensure accountability of financial statements prepared by management and also ensuring shariah aspects are met perfectly by IFIs. Because if there is a failure in the implementation of shariah complience, stakeholders will loss their trust in the IFIs even Islam itself. Therefore, this study will discuss about the current practice of audit shariah in Indonesia. the discussion of shariah auditing practices are focused on four main issues shariah audit, i.e the framework, scope, qualifications and independence of auditors of sharia. This study was conducted using a survey method, in the form of questionnaires that measured with a likert scale to the three groups of respondents (SSB and internal auditors; external auditors, accounting academicians). These studies suggest that the audit practice of sharia in Indonesia has been going well
\end{abstract}

Keywords: Shariah Audit, SSB, Stakeholder, IFIs

ABSTRAK: Lembaga keuangan Syariah (LKS) telah berkembang pesat sejak beberapa tahun terakhir. Ini menimbulkan masalah sesuai Syariah di LKS dan kebutuhan baru fungsi audit, audit Syariah. Fungsi untuk memastikan akuntabilitas laporan keuangan disiapkan oleh manajemen dan juga memastikan Syariah aspek dipenuhi dengan sempurna oleh LKS. Karena jika ada kegagalan dalam pelaksanaan complience Syariah, stakeholder akan kehilangan kepercayaan mereka dalam Islam bahkan LKS sendiri. Oleh karena itu, studi ini akan membahas tentang praktek audit Syariah di Indonesia saat ini. Diskusi tentang syariah audit praktik berfokus pada empat masalah utama Syariah audit, yaitu kerangka, ruang lingkup, kualifikasi dan independensi dari auditor Syariah. Penelitian ini dilakukan menggunakan metode survey, dalam bentuk kuesioner yang diukur dengan Skala Likert kepada tiga kumpulan responden (DPS dan auditor internal, auditor eksternal, akademisi akuntansi). Studi ini menunjukkan bahwa praktek audit Syariah di Indonesia telah berjalan dengan baik.

Kata Kunci: Audit Syariah, DPS, Pemangku Kepentingan, LKS

\footnotetext{
${ }^{1}$ Draft pertama: 20 November 2014; Revisi: 3 Januari 2015; Diterima: 1 Februari 2015

Penulis dapat dikontak melalui: sepky.mardian@gmail.com
} 


\section{PENDAHULUAN}

Market share perbankan syariah saat ini masih berada pada kisaran 5\% dari pangsa pasar nasional. Ini menunjukkan bahwa kepercayaan masyarakat secara umum masih rendah terhadap LKS, diantaranya terhadap kepatuhan syariah (shariah compliance) LKS. Kepatuhan syariah merupakan pilar utama dan pembeda LKS dengan lembaga keuangan konvensional (Mardian, 2015). Masih terdapat adanya keraguan masyarakat terhadap kepatuhan syariah di bank syariah (Bank Indonesia dan Institut Pertanian Bogor, 2004).

Dalam penelitian tentang perilaku nasabah Islamic Bank di Bahrain ditemukan bahwa keputusan nasabah memilih bank syariah lebih didorong oleh faktor keagamaan terkait ketaatan perbankan terhadap prinsip-prinsip Islam. Selain itu, menurut Chapra (2002) dalam (Junusi, 2012), kegagalan dalam penerapan prinsip syariah akan membuat nasabah pindah ke bank lain sebesar 85\%. Junsu (2012) menjelaskan, hasil penelitian Bank Indonesia menyatakan bahwa nasabah yang menggunakan jasa bank syariah, sebagian memiliki kecenderungan untuk berhenti menjadi nasabah antara lain karena keraguan akan konsistensi penerapan prinsip syariah. Dengan demikian pemenuhan prinsip syariah oleh pengelola bank syariah dibutuhkan untuk menumbuhkan kepercayaaan seluruh stakeholders (Wardayati, 2011).

Kebutuhan atas kepastian pemenuhan syariah ini mendorong munculnya fungsi audit baru, yaitu audit syariah. Dalam hal ini, auditor syariah memegang peran krusial untuk memastikan akuntabilitas laporan keuangan dan pemenuhan aspek syariah. Sehingga stakeholder merasa aman berinvestasi dan dana yang dimiliki oleh LKS dapat dipastikan telah dikelola dengan baik dan benar sesuai syariat Islam.

Audit yang ada saat ini merupakan bagian dari sistem keuangan konvensional yang lebih menilai aspek ekonomi saja. Seiring perkembangan keilmuan dan teknologi, aspek diluar ekonomi mulai menjadi sorotan untuk dinilai dalam audit. Hal ini ditandai dengan munculnya lingkup audit lain seperti performance audit, social and enviromental audit dan saat ini mulai berkembang pula audit syariah (Ibrahim, 2008)

Namun dalam penerapannya audit syariah memiliki tantangan tersendiri. Menurut (Kasim, Ibrahim, Hameed, \& Sulaiman, 2009) bahwa ada gap antara harapan dan praktik audit syariah yang berlangsung saat ini. Setidaknya ada 4 faktor utama yang menjadi kendala besar penerapan audit yang berdasarkan hukum syariah tersebut, yaitu kerangka kerja, ruang lingkup, kualifikasi dan isu terkait independensi. Tantangan lain adalah peran dewan pengawas syariah (DPS) sebagai auditor syariah. DPS tidak memiliki kekuatan yang mengikat dan memaksa seperti seharusnya. DPS hanya sebatas mengeluarkan fatwa tanpa kekuasan hukum yang mampu memaksa menerapkan hal tersebut dan juga proses pengangkatannya yang dipilih langsung oleh LKS itu sendiri, hal ini juga menimbulkan isu independensi (Abdul-Razzaq, 2009).

Di Indonesia sendiri menurut penelitian yang dilakukan (Kasim, Sanusi, Mutamimah, \& Handoyo, 2013), terlihat bahwa praktisi audit di Indonesia masih mencari pedoman aturan yang tepat bagi lingkup, regulasi kerangka kerja, kualifikasi dan independensi auditor syariah. Sebagai negara dengan mayoritas penduduknya adalah muslim, jumlah auditor syariah yang dimiliki masih sangat terbatas. Hingga tahun 2014 hanya sekitar 54 orang yang memiliki Sertifikasi Akuntansi Syariah (SAS) yang dikeluarkan oleh Ikatan Akuntan Indonesia(IAI, 2013). Dan akuntan publik yang dapat mengaudit LKS berdasarkan data yang dikeluarkan Otoritas Jasa Keuangan (OJK) baru berjumlah sekitar 30 KAP. 


\title{
KERANGKA TEORITIS DAN PENGEMBANGAN HIPOTESIS
}

\author{
Konsep Umum Good Corporate Governance
}

Cadburry Commite mendefinisikan GCG sebagai berikut :

"Corporate Governance adalah sistem yang mengarahkan dan mengendalikan perusahaan dengan tujuan agar mencapai keseimbangan antara kekuatan kewenangan yang diperlukan oleh perusahaan, untuk menjamin kelangsungan eksistensinya dan pertanggungjawaban kepada Stakeholders. Hal ini berkaitan dengan peraturan kewenangan pemilik, direktur, manajer, pemegang saham dan sebagainya." (Lewis \& Algoud, 2007)

GCG adalah sebuah bentuk akuntabilitas manajemen kepada para stakeholder. Namun, tidak demikian dengan GCG dalam LKS atau yang dikenal dengan SCG (Shariah Corporate Governance). SGC memiliki cakupan yang lebih luas. Akuntabilitas perusahaan tidak hanya ditujukan pada stakeholder namun pada tujuan yang lebih tinggi, Allah SWT. Sehingga, LKS memiliki kewajiban untuk mematuhi prinsip-prinsip syariah (sharia compliance) dan etika Islam dalam menjalankan bisnisnya.

Dengan demikian dapat disimpulkan, dalam sudut pandang fungsional GCG dan SGC memiliki kesamaan yaitu untuk menjaga hak dan kepentingan stakeholder atas akuntabilitas kinerja manajemen. Dan kedua konsep tata kelola tersebut menjadikan audit sebagai sebuah elemen penting untuk menjaga akuntabilitas tersebut. Namun, GCG dalam Islam yang bukan hanya bentuk akuntabilitas kepada stakeholder tetapi juga pada Allah SWT, menjadikan pengawas terhadap syariah adalah hal yang mutlak.

\section{Auditing dalam Pandangan Islam}

Auditing dalam pandangan Islam adalah bukan sesuatu yang relatif baru. Audit muncul setelah kemunculan lembaga keuangan syariah sekitar tahun 1980-an yang membutuhkan fungsi audit berdasarkan pada prinsip Islam. Dalam sejarah Islam, pada masa Nabi Muhammad SAW dan khulafah rasyidin terdapat sebuah lembaga yang berfungsi seperti auditor, yaitu lembaga hisbah yang bertujuan untuk membantu umat manusia dalam beribadah kepada Allah dengan memastikan bahwa hak Allah maupun hak asasi manusia lainya telah diperhatikan dan dilaksanakan dengan benar (Shafeek, 2013; Kasim N. , 2010; Imran, Ahmad, \& Bhuiyan, 2012). Murtuza (2000) menyebut lembaga hisbah ini terus ada dan berperan sampai Islam tersebar di Spanyol (Kasim N. , 2010). Yacoob (2012) menyatakan pula bahwa peran auditor syariah menyerupai peran muhtasib dalam lembaga hisbah tradisional pada masa awal keIslaman. Dalam Alquran pun terdapat ayat-ayat atau dalil yang apabila ditafsirkan maka akan menunjukan bahwa Islam mengenal fungsi audit yang ada saat ini seperti dalam QS. Al Insiqaq: 6-9, Al Infithar: 10-12, An Naml: 20-21; dan Albaqarah 282.

Harahap (2002) menyatakan fungsi audit dilakukan berdasarkan pada sikap ketidakpercayaan atau kehati-hatian terhadap kemungkinan laporan yang disajikan oleh perusahaan mengandung informasi yang tidak benar yang dapat merugikan pihak lain yang tidak memiliki kemampuan akses terhadap sumber informasi. Dalam fungsi ini disebut sebagai "tabayyun" atau mengecek kebenaran berita yang disampaikan dari sumber yang kurang dipercaya sebagaimana dinyatakan dalam Al Hujuraat (49) ayat 6.

Seorang auditor memiliki kewajiban untuk menyaksikan bahwa informasi yang disajikan dalam laporan keuangan adalah benar atau tidak. Apabila dikomparasikan dalam konteks sistem keuangan Islami, audit syariah hadir sebagai sebuah sistem yang memeriksa kepatuhan operasi-operasi keuangan syariah berdasarkan hukum syariah (Shafeek, 2013). Sehingga, dapat disimpulkan Islam telah mengenal fungsi audit sejak lama, yaitu dalam bentuk lembaga hisbah yang memiliki tugas serupa dengan konsep audit (Harahap, 2002). 


\section{Praktik Audit Syariah dalam LKS}

Audit syariah adalah sebuah proses pemeriksaan sistematis atas kepatuhan seluruh aktivitas LKS terhadap prinsip syariah yang meliputi laporan keuangan, produk, penggunaan IT, proses operasi, pihak-pihak yang terlibat dalam aktivitas bisnis LKS, dokumentasi dan kontrak, kebijakan dan prosedur serta aktvitas lainnya yang memerlukan ketaatan terhadap prinsip syariah (Sultan, 2007; Yaacob, 2012)

Tujuan utama auditing LKS adalah untuk memberikan opini atas laporan keuangan yang disiapkan manajemen (perusahaan), dalam semua aspek material telah sesuai dengan hukum dan prinsip syariah, AAOIFI, dan standar akuntansi nasional negara bersangkutan. Dengan kata lain audit dalam LKS tidak hanya terbatas pada peraturan umum audit financial tetapi juga pandangan syariah (Hanifa, 2010).

\section{Key Player dalam Audit Syariah}

Hanifah (2010), menjabarkan bahwa dalam audit syariah terdapat beberapa pemain kunci yang memiliki peranannya masing-masing:

a. DPS (Dewan Pengawas Syariah) dan Internal Auditor

DPS merupakan pihak yang memainkan peran kunci dalam keseluruhan audit dan kerangka tata kelola perusahaan dalam LKS (Kasim \& Sanusi, 2013; Karim, 1990). DPS berperan untuk merumuskan kebijakan dan pedoman yang harus diikuti oleh manajemen dalam kegiatan mereka, termasuk persetujuan atas produk yang dikeluarkan dan juga melakukan shariah review, yang merupakan pemeriksaan untuk memastikan bahwa kegiatan yang dilakukan oleh LKS tidak bertentangan dengan prinsip-prinsip syariah. Dalam menjalankan peran sebagai shariah review DPS dibantu oleh auditor internal sebagai pelaksana harian. Yacoob (2012) berpendapat bahwa internal auditor dapat menjalankan fungsi auditor syariah bila memiliki pengetahuan dan keahlian syariah yang memadai. Tujuan utamanya adalah untuk memastikan sistem pengendalian intern yang baik dan efektif yang mengikuti syariah secara ketat.

\section{b. Auditor Eksternal}

Auditor eksternal memiliki peran yang unik dalam audit syariah, bukan hanya berperan dalam melakukan audit keuangan tetapi juga melakukan shariah compliance test untuk memastikan kepatuhan shariah dari perusahaan atau LKS. Proses audit tersebut dilakukan secara terstruktur, dimulai dengan perencanaan audit dan diakhir dengan pemberian opini oleh auditor terkait laporan keuangan yang disiapkan telah sesuai fatwa, AAOIFI serta standar dan praktik akuntansi yang berlaku dalam negeri yang bersangkutan.

\section{Framework Audit Syariah}

Framework (kerangka kerja) audit merupakan aturan, arahan dan acuan seorang auditor dalam melaksanakan audit sehingga hasil audit berkualitas, dapat dipertanggungjawabkan dan sesuai dengan aturan yang berlaku sehingga dapat diperbandingkan dan digunakan oleh para stakeholder dalam mengambil keputusan.

Apabila framework tersebut dikombinasikan dengan prinsip dan aturan syariah yang berlaku, maka audit syariah dapat dilaksanakan sebagaimana mestinya. Hal tersebut disebabkan konsep audit syariah dilaksanakan untuk mengukur sejauh mana organisasi mematuhi aturan dan regulasi yang diberikan oleh Allah SWT dan bukan sekedar untuk memastikan keadilan dan kebenaran laporan keuangan yang disiapkan manajemen (Rahman, 2008).

Menurut (Yaacob \& Donglah, 2012) dan penelitian (Kasim, Ibrahim, Hameed, \& Sulaiman, 2009), mayoritas responden sepakat berpendapat bahwa kerangka audit syariah 
harus berbeda dari kerangka audit yang konvensional. Hal tersebut disebabkan framework audit konvensional dianggap tidak mampu meng-cover tujuan utama audit syariah, yaitu memastikan bahwa LKS dalam seluruh aktivitasnya telah mengimplementasikan dan memenuhi prinsip dan aturan syariah yang diperlukan.

\section{Ruang Lingkup Audit Syariah}

Hanifah (2010) menjelaskan bahwa lingkup audit yang dicakup dalam audit syariah lebih luas dibandingkan dengan audit konvensional. Audit syariah harus memastikan kebenaran, keadilan dan relevansi laporan keuangan yang diterbitkan manajemen dan memastikan bahwa manajemen telah melakukan tugasnya sesuai dengan hukum dan prinsip Islam, serta memastikan manajemen telah berusaha melaksanakan tujuan syariah (maqasid al-shariah) sebagai upaya untuk melindungi dan meningkatkan kehidupan umat manusia dalam semua dimensi. Sedangkan menurut (Yaacob \& Donglah, 2012), lingkup audit syariah lebih luas yaitu mencakup "social behavior" (perilaku social) dan kinerja organisasi termasuk hubungannya dengan selruh stakeholder. Ruang lingkup audit syariah dalam LKS yaitu laporan keuangan; operasional; struktur organisasi dan manajemen; dan sistem informasi teknologi (Sultan, 2007).

Berdasarkan penjabaran di atas diketahui bahwa lingkup audit syariah bukan hanya terkait aktivitas ekonomi dan laporan keuangan manajemen namun juga mengaitkan pengaruh sosial dan lingkungan dalam proses pengauditannya hal ini tidak lepas dari hukum Islam yang memang secara luas mengatur setiap sendi kehidupan manusia dan tujuan besarnya adalah mempertemukan antara konsep audit dengan maqosid syariah (Kasim, Ibrahim, Hameed, \& Sulaiman, 2009; Yaacob \& Donglah, 2012; Shafeek, 2013).

\section{Kualifikasi Auditor Syariah}

Menurut standar yang dikeluarkan oleh AAOIFI (2010) seorang auditor selain memiliki pengetahuan dibidang akuntansi/auditing juga harus memiliki pengetahuan terkait prinsip dan hukum Islam tetapi tidak perlu sedetail pengetahuan yang harus dimiliki oleh Dewan Pengawas Syariah (DPS). Selain itu, dari penelitian yang dilakukan oleh (Kasim, Ibrahim, Hameed, \& Sulaiman, 2009) hanya 5,9 \% dari responden yang memiliki kedua kualifikasi (akuntansi/auditing dan syariah) tersebut, sedangkan jumlah praktiksi audit syariah LKS di Malaysia yang menjadi responden sebanyak 69\%. Sedangkan menurut penelitian lain yang dilakukan oleh Mulyani (2007) dalam (Ibrahim, 2008) seorang auditor harus memiliki kualifikasi dibidang akuntansi yang kemudian memiliki sertifikat spesialisasi dalam bidang auditing syariah. Dan dalam penelitian lain pun demikian, mayoritas responden mengemukakan bahwa auditor syariah perlu memiliki dua kualifikasi yang mumpuni, yaitu dibidang akuntasi/auditing dan di bidang syariah (terutama fiqh muamalah) (Khan, 1985).

\section{Independensi Auditor Syariah}

Menurut Kasim (2009), audit dalam keuangan Islam memiliki fungsi sosial yang harus memberikan manfaat bagi umat. Manfaat sepenuhnya dari audit syariah tidak akan bisa direalisasikan apabila auditor syariah tidak berdiri secara mandiri. Peran utama dari seorang auditor syariah adalah untuk menjaga atau mengawasi syariah compliance lembaga keuangan syariah. Auditor perlu dan harus independen dalam sikap maupun kelembagaan (Kasim \& Sanusi, 2013; Kasim, Ibrahim, Hameed, \& Sulaiman, 2009; Yaacob \& Donglah, 2012; Shafeek, 2013). 


\section{Penelitian Terdahulu}

Kasim, et.al (2009) mengungkapkan empat hal (kerangka kerja, ruang lingkup, kualifikasi dan independensi) yang memiliki gap apa yang benar-benar inginkan tidak sesuai dengan praktek yang sebenarnya. Minarni (2013) menyatakan adanya pengawasan pada bank syariah, audit syariah dan GCG tidak berarti dapat menggantikan tugas manajemen bank dan tidak menjamin bank bebas dari krisis, kerugian maupun kebangkrutan. Selanjutnya Kasim, et.al (2013) menemukan praktek syariah audit di LKS menjadi regulasi, baik di Indonesia, Malaysia, atau bagian lain dunia yang mempraktikkan Islam perbankan dan keuangan. Malaysia adalah satu negara yang sudah mulai mengatur praktik audit syariah.

\section{METODE PENELITIAN}

Penelitian deskrptif ini berupaya untuk menggambarkan situasi dan kondisi lapangan mengenai variabel praktik audit syariah di Indonesia. Variabel yang digunakan adalah praktik audit syariah di Indonesia, yang difokuskan pada empat hal yaitu kerangka kerja (framework) audit syariah, lingkup (scope) audit syariah, independensi (independence) auditor syariah dan kualifikasi (qualification) auditor syariah

Tabel 1. Instrumen Penelitian

\begin{tabular}{|c|c|c|}
\hline $\begin{array}{c}\text { Sub } \\
\text { Variabel }\end{array}$ & Indikator (Harapan) & Sumber \\
\hline $\begin{array}{l}\text { Praktik } \\
\text { Audit } \\
\text { Syariah }\end{array}$ & $\begin{array}{l}\text { a. Kerangka kerja audit yang digunakan telah } \\
\text { mengakomodir prinsip dan aturan syariah } \\
\text { b. Kerangka kerja audit yang dipergunakan berbeda } \\
\text { dengan kerangka kerja audit konvensional (kerangka } \\
\text { kerja khusus audit syariah) } \\
\text { c. Lingkup pemeriksaan audit syariah harus lebih luas } \\
\text { dari audit konvensional, yaitu mencakup empat hal : } \\
\text { - Financial Statements Audit (Audit Laporan } \\
\text { Keuangan) } \\
\text { - Operational Aspects of Islamic Banks (Aspek - } \\
\text { aspek Operasional Bank Syariah) } \\
\text { - Organizational Structure and personnel } \\
\text { Management (Struktur organisasi dan personil } \\
\text { manajemen) } \\
\text { Information and Technology Systems (Sistem } \\
\text { Teknologi dan Informasi) } \\
\text { d. Seorang auditor syariah harus memiliki pengetahuan } \\
\text { (kualifikasi) dibidang akuntansi/auditing maupun } \\
\text { syariah (fiqh muamalah) baik dalam bentuk gelar } \\
\text { profesional, trainning maupun sertifikasi } \\
\text { e. Auditor independen secara mental/sikap dan } \\
\text { Auditor independen } \\
\text { penampilan/kelembagaan }\end{array}$ & $\begin{array}{l}\text { Kasim (2009); } \\
\text { Yacoob \& } \\
\text { Donglah (2012); } \\
\text { Rahman (2013); } \\
\text { ASIFI-AAOIFI } \\
\text { (2009) } \\
\text { Kasim (2009) }\end{array}$ \\
\hline
\end{tabular}

Teknik sampling yang digunakan dalam penelitian ini adalah purposive sampling, dengan jumlah data 60 responden, yang terlibat langsung sebanyak 30 responden dan yang tidak terlibat langsung 30 responden. Puposive sampling dipilih karena beberapa faktor 
yaitu, kendala sumberdaya yang terbatas dan ketepatan sampel yang dipilih. Kriteria sampel yang dipilih adalah responden yang dianggap memiliki pengetahuan mengenai mekanisme kerja LKS dan memiliki pengetahuan dasar tentang audit konvensional/syariah ataupun sistem pengawasan LKS. Berdasarkan hal tersebut maka responden penelitian ni adalah DPS (Dewan Pengawas Syariah), Internal Auditor, Eksternal Auditor mewakili responden yang terlibat langsung dan Mahasiswa/i yang mempelajari akuntansi syariah dan/atau audit pada LKS (audit syariah) mewakili responden yang tidak terlibat secara langsung.

Penelitian ini menggunakan data primer dan sekunder. Data primer yang digunakan diperoleh melalui survey lapangan dengan metode pengumpulan data menggunakan menggunakan kuisioner. Data sekunder berupa data yang diperoleh melalui sumbersumber yang tersedia dan dipublikasikan kepada masyarakat. Data tersebut bisa merupakan data internal atau eksternal organisasi dan dapat diakses melalui internet maupun penelusuran dokumen.

\section{Karakteristik Responden}

Dalam penelitian ini, kuesioner disebarkan kepada pihak yang terlibat langsung maupun yang tidak terlibat langsung dalam praktik audit syariah di Indonesia. Pihak yang terlibat langsung diwakili oleh DPS/Internal Audit dan Eksternal Auditor sedangkan pihak yang tidak terlibat langsung diwakili oleh mahasiswa/i yang mempelajari akuntansi syariah dan atau auditing syariah. Kuesioner disebar baik secara langsung maupun melalui media internet berupa kuesioner elektronik yang disediakan oleh google form. Kuesioner yang terkumpul adalah sebanyak 6o kuesioner dari sekitar 100 kuesioner yang disebar. Dengan demikian jumlah responden dalam penelitian ini adalah 6o responden yaitu, 30 responden (50\%) adalah mahasiswa/i akuntansi dan/auditing syariah; 19 responden (32\%) adalah DPS/Internal Auditor dan 11 responden (18\%) adalah Eksternal Auditor.

\section{HASIL DAN PEMBAHASAN}

\section{Praktik Audit Syariah di Indonesia}

Variabel praktik audit syariah di Indonesia yang digunakan dalam pada penelitian ini yaitu, kerangka kerja, ruang lingkup, kualifikasi dan independensi auditor syariah. Berdasarkan pada keempat isu tersebut akan diketahui bagaimana praktik audit syariah di Indonesia berjalan, apakah sesuai dengan harapan atau terjadi gap antara harapan tersebut dan kenyataannya. Untuk itu, terdapat 9 pernyataan dari 4 indikator yang digunakan untuk menilai praktik audit syariah tersebut.

\section{Kerangka Kerja Audit Syariah}

Kerangka kerja dalam pelaksanaan audit merupakan hal yang sangat penting. Kerangka kerja berfungsi sebagai acuan bagi auditor melaksanakan pemeriksaan pada perusahaan. Sehingga tidak semua aspek harus diperiksa oleh auditor, hanya yang memiliki resiko dan yang terkait yang harus diuji. Namun, kerangka kerja audit yang ada saat ini adalah kerangka kerja audit yang berdasarkan pada standar maupun aturan untuk perusahaan konvensional. Landasan utama audit konvensional hanya berorientasi pada hukum-hukum yang berasal dari konsensus masyarakat baik nasional maupun internasional. Sedangkan audit syariah memiliki landasan hukum tambahan yaitu aspek syariah berupa hukum dan prinsip Islam yang berasal dari Allah SWT. Aspek religiusitas ini tidak diakomodir oleh standar audit konvensional. Sehingga, audit syariah memerlukan standar acuan yang berbeda. Dan kerangka kerja audit syariah haruslah memiliki acuan tersendiri.

Dengan demikian harapan bagaimana kerangka kerja yang digunakan untuk melaksanakan audit syariah seharusnya adalah kerangka kerja yang mengakomodir prinsip 
dan hukum Islam dan juga memiliki kerangka kerja khusus yang berbeda dari audit konvensional. Untuk melihat bagaimana kesesuaian kerangka kerja audit syariah dengan harapan tersebut di Indonesia saat ini, maka dapat dilihat melalui tabel di bawah ini:

Tabel 2. Jawaban Responden Mengenai Kerangka Kerja Audit Syariah

\begin{tabular}{|c|c|c|c|c|c|c|c|c|c|c|}
\hline No. & Item Pertanyaan & & \multicolumn{2}{|c|}{$\begin{array}{c}\text { DPS/Internal } \\
\text { Auditor }\end{array}$} & \multicolumn{2}{|c|}{$\begin{array}{l}\text { Eksternal } \\
\text { Auditor }\end{array}$} & \multicolumn{2}{|c|}{$\begin{array}{l}\text { Mahasiswa/i } \\
\text { Jurusan } \\
\text { Akuntansi } \\
\text { Syariah }\end{array}$} & \multicolumn{2}{|c|}{ Total } \\
\hline \multirow[t]{8}{*}{1} & \multirow{8}{*}{$\begin{array}{l}\text { Kerangka kerja } \\
\text { (framework) audit pada } \\
\text { LKS saat ini telah sesuai } \\
\text { dengan aturan dan } \\
\text { prinsip syariah }\end{array}$} & & $\mathrm{F}$ & $\%$ & $\mathrm{~F}$ & $\%$ & $\mathrm{~F}$ & $\%$ & $\mathrm{~F}$ & $\%$ \\
\hline & & STS & o & o & $\mathrm{o}$ & o & o & o & o & o \\
\hline & & TS & o & $\mathrm{o}$ & 1 & 9,1 & 5 & 16,7 & 6 & 10 \\
\hline & & $\mathrm{N}$ & 7 & 36,8 & 5 & 45,5 & 12 & 40 & 24 & 40 \\
\hline & & $\mathrm{S}$ & 10 & 52,6 & 5 & 45,5 & 12 & 40 & 27 & 45 \\
\hline & & SS & 2 & 10,5 & o & o & 1 & 3,3 & 3 & 5 \\
\hline & & Total & 19 & 100 & 11 & 100 & 30 & 100 & 60 & 100 \\
\hline & & Mean & \multicolumn{2}{|c|}{3,74} & \multicolumn{2}{|c|}{3,36} & \multicolumn{2}{|c|}{3,3} & \multicolumn{2}{|c|}{3,47} \\
\hline \multirow[t]{7}{*}{2.} & \multirow{7}{*}{$\begin{array}{l}\text { Kerangka kerja } \\
\text { (framework) audit pada } \\
\text { LKS saat ini telah } \\
\text { mencakup semua aspek } \\
\text { yang dibutuhkan dalam } \\
\text { pelaksanaan audit } \\
\text { syariah }\end{array}$} & STS & $\mathrm{o}$ & $\mathrm{o}$ & $\mathrm{o}$ & 0 & $\mathrm{o}$ & $\mathrm{o}$ & $\mathrm{o}$ & $\mathrm{o}$, \\
\hline & & TS & 4 & 21 & 1 & 9,1 & 11 & 36,7 & 16 & 26,7 \\
\hline & & $\mathrm{N}$ & 6 & 31,6 & 4 & 36,4 & 5 & 17 & 15 & 25,0 \\
\hline & & $\mathrm{S}$ & 7 & 36,8 & 6 & 54,5 & 14 & 47 & 27 & 45,0 \\
\hline & & SS & 2 & 10,5 & $\mathrm{o}$ & $\mathrm{o}$ & o & $\mathrm{o}$ & 2 & 3,3 \\
\hline & & Total & 19 & 100 & 11 & 100 & 30 & 100 & 60 & 100 \\
\hline & & Mean & \multicolumn{2}{|c|}{3,37} & \multicolumn{2}{|c|}{3,45} & \multicolumn{2}{|c|}{3,1} & \multicolumn{2}{|c|}{3,31} \\
\hline \multirow[t]{7}{*}{3.} & \multirow{7}{*}{$\begin{array}{l}\text { Indonesia telah memiliki } \\
\text { kerangka kerja } \\
\text { (Framework) audit } \\
\text { khusus yang membantu } \\
\text { auditor syariah } \\
\text { (DPS/Internal } \\
\text { Auditor/Eksternal } \\
\text { Auditor) dalam praktik } \\
\text { audit pada LKS (audit } \\
\text { syariah) }\end{array}$} & STS & o & o & o & o & o & o & o & o \\
\hline & & TS & 3 & 15,8 & 5 & 45,5 & 9 & 30,0 & 17 & 28 \\
\hline & & $\mathrm{N}$ & 8 & 42,1 & 1 & 9,1 & 13 & 43,3 & 22 & 37 \\
\hline & & $S$ & 7 & 36,8 & 5 & 45,5 & 7 & 23,3 & 19 & 32 \\
\hline & & SS & 1 & 5,3 & $\mathrm{o}$ & 0,0 & 1 & 3,3 & 2 & 3 \\
\hline & & Total & 19 & 100 & 11 & 100 & 30 & 100 & 60 & 100 \\
\hline & & Mean & & & & & & & & ,11 \\
\hline \multicolumn{3}{|c|}{ Total Mean } & \multicolumn{2}{|c|}{3,44} & \multicolumn{2}{|c|}{3,27} & \multicolumn{2}{|c|}{3,13} & \multicolumn{2}{|c|}{3,29} \\
\hline
\end{tabular}

Sumber: data diolah (2015)

Berdasarkan tabel diatas, jumlah skor rata-rata tanggapan responden tentang kerangka kerja audit syariah di Indonesia adalah skor responden DPS/internal auditor sebesar 3,44; rata-rata skor responden eksternal auditor sebesar 3,27 dan rata-rata skor responden mahasiswa/i akuntansi syariah sebesar 3,13 dengan total rata-rata skor seluruh reponden sebesar 3,29. Dalam pengklasifikasian melalui garis kontinum jumlah total ratarata skor seluruh reponden termasuk dalam kategori cukup sesuai. 
Merujuk pada pengklasifikasian tersebut, maka dapat diartikan bahwa tanggapan responden tentang kerangka audit syariah di Indonesia cukup sesuai dengan harapan, yakni telah cukup sesuai dan cukup mengakomodir aspek syariah dalam kerangka kerja yang digunakan dan telah memiliki kerangka kerja khusus yang cukup untuk melaksanakan audit LKS (audit syariah). Namun, dikarenakan hanya termasuk ke dalam kategori cukup sesuai dengan harapan, maka hal ini mengindikasikan bahwa kerangka kerja belum sepenuhnya sesuai dengan harapan yang diinginkan dan perlu untuk ditinjau serta diperbaiki.

Akan tetapi, kerangka kerja yang dimaksud di atas, yang digunakan untuk melaksanakan audit pada LKS, baru sebatas panduan audit syariah yang dikeluarkan oleh IAI (Ikatan Akuntan Indonesia) pada tahun 2005 dan masih berkisar pada audit laporan keuangan. Seiring berjalannya waktu banyak terjadi revisi pada PSAK Syariah sehingga panduan tersebut perlu untuk direvisi kembali. Saat ini audit laporan keuangan LKS, yang telah berjalan dengan baik karena sudah adanya PSAK Syariah sebagai pedoman yang telah mengakomodir aspek syariah di dalamnya. Walaupun teknik audit yang digunakan masih bedasarkan audit konvensional. Artinya auditor melakukan pemeriksaan dengan cara konvensional pada LKS. Namun, hal ini tetap perlu diapresiasi mengingat memang masih terjadi lack terhadap kerangka kerja lengkap audit syariah beserta prosedurnya yang dapat digunakan sebagai pedoman dan sesuai dengan apa yang dibutuhkan.

Sebagaimana yang dijelaskan oleh Minarni (2013), kegiatan audit pada LKS di Indonesia terdiri dari tiga lapis, pertama, auditor internal melakukan pengujian pada laporan keuangan LKS memastikan kesesuaian dengan standar akuntansi yang berlaku umum dan tidak terjadi salah saja material; kedua, auditor eksternal melaksanakan pengujian atas hasil kinerja auditor internal tersebut, dan ketiga, auditor eksternal yang memiliki sertifikasi SAS melakukan pemeriksaan untuk memastikan produk dan transaksi LKS telah sesuai dengan prinsip dan aturan syariah yang berkenaan dengan laporan keuangan.

Dalam praktiknya, menyangkut pada audit syariah di luar aspek laporan keuangan saat ini, merupakan tanggung jawab Dewan Pengawas Syariah (DPS). Sedangkan mengenai kerangka kerja pelaksanaan tugas DPS sebagai auditor syariah hingga saat ini Indonesia masih belum dimiliki. Kerangka besar tugas dan wewenang DPS memang telah diatur melalui UU No. 21/2008 dan Peraturan Bank Indonesia terkait, akan tetapi aturan tersebut belum memberikan arahan prosedur yang jelas bagi pekerjaan DPS. Sehingga belum terjadi standarisasi pemeriksaan yang dilakukan oleh DPS. Dengan demikian pemeriksaan yang dilakukan antara DPS yang satu dengan DPS yang lain bisa saja berbeda satu sama lain. Adapun kerangka kerja DPS diatur dalam panduan Surat Edaran BI No. 8/19/DPBS tanggal 24 Agustus 2006 Perihal Pedoman Pengawasan Syariah dan Tata Cara Pelaporan Hasil Pengawasan bagi DPS. Laporan hasil pengawasan Syariah beserta kertas kerja pengawasan yang telahdisusun oleh DPS, sesuai dengan peraturan ini, disampaikan kepada Direksi, Komisaris, DSN, dan juga BI. Selain itu dalam surat edaran tersebut juga dibahas mengenai Laporan hasil pengawasan.

Dengan demikian, hasil penelitian ini mendukung penelitian terdahulu yang dilakukan oleh (Kasim, Sanusi, Mutamimah, \& Handoyo, 2013) di Indonesia, yang menghasilkan temuan bahwasanya Indonesia masih mencari kerangka kerja yang tepat bagi pelaksanaan audit syariah di dalam negeri. Dan untuk mengatasi hal tersebut Indonesia menyusun panduan audit syariah untuk digunakan sebagai acuan pelaksanaan audi saat ini. Dan responden menilai bahwa keberadaan panduan yang dikeluarkan IAI dan Bank Indonesia tersebut cukup baik.

Oleh karena itu, secara umum dapat disimpulkan bahwa Indonesia belum memiliki kerangka kerja pelaksanaan audit syariah yang sesuai dengan harapan semestinya. Namun, telah memiliki panduan audit syariah tersendiri yang mengakomodir prinsip dan hukum 
syariah untuk melaksanakan audit laporan keuangan LKS, dengan adanya PSAK syariah yang dikeluarkan IAI (Ikatan Akuntan Indonesia). Meskipun kerangka kerja tersebut masih berupa panduan dan bukan standar baku yang khusus mengatur pelaksanaan audit syariah secara komprehensif sebagaimana yang telah dimiliki standar audit konvensional serta belum secara lengkap mengatur pemeriksaan semua aspek yang memiliki resiko kepatuhan syariah dalam LKS disebabkan hal yang sama terjadi pula pada kerangka kerja DPS yang saat ini hanya berupa pedoman yang dikeluarkan BI melalui Surat Edaran Bank Indonesia.

\section{Ruang Lingkup Audit Syariah}

Ruang lingkup pemeriksaan audit kini tidak hanya terbatas pada laporan keuangan. Namun, saat ini sejalan dengan kebutuhan masyarakat maka lingkup audit pun semakin berkembang luas pada hal-hal diluar laporan keuangan, yakni seperti audit kinerja, audit lingkungan, audit SDM dan lain-lain. Lingkup audit tersebut tidak lagi hanya berkaitan dengan laporan keuangan ataupun aktivitas ekonomi perusahaan tetapi hal yang lebih luas di luar itu.

Sejalan dengan hal tersebut, beberapa tahun belakangan audit syariah mulai berkembang seiring pesatnya perkembangan LKS saat ini. Audit syariah sangat berbeda dengan audit konvensional. Aspek religiusitas menjadi landasan utamanya, hal ini lah yang tidak tercover oleh apapun bentuk audit konvensional saat ini. Karena tujuan utama audit syariah adalah memastikan perusahaan telah melaksanakan semua hukum ekonomi yang berlaku, termasuk hukum dan prinsip Islam terkait hal itu.

Untuk mengetahui apakah lingkup audit syariah di Indonesia saat ini telah sesuai dengan harapan atau belum, maka dapat dilihat melalui tabel berikut ini:

\section{Tabel 3. Hasil Jawaban Responden Mengenai Ruang Lingkup Audit Syariah}

\begin{tabular}{|c|c|c|c|c|c|c|c|c|c|c|}
\hline $\begin{array}{l}\mathrm{N} \\
\mathrm{o}\end{array}$ & Item Pertanyaan & & \multicolumn{2}{|c|}{$\begin{array}{c}\text { DPS/Intern } \\
\text { al Auditor }\end{array}$} & \multicolumn{2}{|c|}{$\begin{array}{l}\text { Eksterna } \\
1 \text { Auditor }\end{array}$} & \multicolumn{2}{|c|}{$\begin{array}{l}\text { Mahasisw } \\
\text { a/i } \\
\text { Jurusan } \\
\text { Akuntans } \\
\text { i Syariah }\end{array}$} & \multicolumn{2}{|c|}{ Total } \\
\hline \multirow[t]{8}{*}{4} & \multirow{8}{*}{$\begin{array}{l}\text { lingkup area audit } \\
\text { dalam LKS yang } \\
\text { dicakup oleh } \\
\text { audit saat ini } \\
\text { telah mencakup } \\
\text { semua aspek yang } \\
\text { memiliki resiko } \\
\text { kepatuhan syariah }\end{array}$} & & $\mathrm{F}$ & $\%$ & $\mathrm{~F}$ & $\%$ & $\mathrm{~F}$ & $\%$ & $\mathrm{~F}$ & $\%$ \\
\hline & & STS & o & o & o & o & o & o & o & o \\
\hline & & TS & o & o & 1 & 9 & 8 & $\begin{array}{r}26 \\
7\end{array}$ & 9 & 15 \\
\hline & & $\mathrm{N}$ & 4 & 21,1 & 5 & 45,5 & 9 & $\begin{array}{r}30, \\
0\end{array}$ & 18 & 30 \\
\hline & & $S$ & 13 & 68,4 & 5 & 45,5 & 10 & 33,3 & 28 & 46,7 \\
\hline & & SS & 2 & 10,5 & o & o & 3 & 10,0 & 5 & 8,3 \\
\hline & & Total & 19 & 100 & 11 & 100 & 30 & 100 & 60 & 100 \\
\hline & & Mean & \multicolumn{2}{|c|}{3,89} & \multicolumn{2}{|c|}{3,36} & \multicolumn{2}{|c|}{3,27} & \multicolumn{2}{|c|}{3,51} \\
\hline \multirow[t]{3}{*}{5} & \multirow{3}{*}{$\begin{array}{l}\text { lingkup audit } \\
\text { pada LKS saat ini } \\
\text { telah mencakup }\end{array}$} & STS & o & o & o & o & o & o & o & o \\
\hline & & TS & o & 0,0 & o & 0,0 & 11 & 36,7 & 11 & 18,3 \\
\hline & & $\mathrm{N}$ & 2 & 10,5 & 6 & 54,5 & 8 & 26 , & 16 & 26,7 \\
\hline
\end{tabular}




\begin{tabular}{|c|c|c|c|c|c|c|c|c|c|c|}
\hline & aspek diluar audit & & & & & & & 6 & & \\
\hline & laporan keuangan & $\mathrm{S}$ & 13 & 68,4 & 5 & 45,5 & 11 & 36,7 & 29 & 48,3 \\
\hline & seperti aspek - & SS & 4 & 21,1 & $\mathrm{o}$ & 0,0 & o & o & 4 & 6,7 \\
\hline & $\begin{array}{l}\text { aspek operasional } \\
\text { JS }\end{array}$ & Total & 19 & 100 & 11 & 100 & 30 & 100 & 60 & 100 \\
\hline & $\begin{array}{l}\text { (akad/kontrak, } \\
\text { prosedur } \\
\text { bisnis,dll), } \\
\text { struktur } \\
\text { organisasi dan } \\
\text { personil } \\
\text { management dan } \\
\text { sistem teknologi } \\
\text { dan informasi }\end{array}$ & Mean & & & & 45 & & & & \\
\hline 6 & Pemeriksaan & STS & o & o & $\mathrm{o}$ & o & o & o & o & 0,0 \\
\hline & kesyariaahan & TS & o & $\mathrm{o}, \mathrm{O}$ & 1 & 9,1 & 4 & 13,3 & 5 & 8,3 \\
\hline & $\begin{array}{l}\text { produk LKS } \\
\text { termasuk ruang }\end{array}$ & $\mathrm{N}$ & 6 & 31,6 & 4 & 36,4 & 6 & $\begin{array}{r}20 \\
0\end{array}$ & 16 & 26,7 \\
\hline & $\begin{array}{l}\text { lingkup audit saat } \\
\text { ini }\end{array}$ & $\mathrm{S}$ & 10 & 52,6 & 6 & 54,5 & 18 & $\begin{array}{r}60 \\
0\end{array}$ & 34 & 56,7 \\
\hline & & SS & 3 & 15,8 & o & 0,0 & 2 & 6,7 & 5 & 8,3 \\
\hline & & Total & 19 & 100 & 11 & 100 & 30 & 100 & 60 & 100 \\
\hline & & Mean & & & & 45 & & & & \\
\hline 7 & Lingkup audit & STS & o & o & o & o & o & o & o & , o \\
\hline & pada LKS telah & TS & 2 & 10,5 & 2 & 18,2 & 3 & 10 & 7 & 11,7 \\
\hline & mencakup islamic & $\mathrm{N}$ & 10 & 52,6 & 7 & 63,6 & 11 & 36,7 & 28 & 46,7 \\
\hline & Social report & $S$ & 6 & 31,6 & 2 & 18,2 & 13 & 43,3 & 21 & 35,0 \\
\hline & & SS & 1 & 5,3 & o & 0,0 & 3 & 10 & 4 & 6,7 \\
\hline & & Total & 19 & 100 & 11 & 100 & 30 & 100 & 60 & 100 \\
\hline & & Mean & & & & oo & & & & \\
\hline & Total Mean & & & & & 32 & & & & \\
\hline
\end{tabular}

Berdasarkan tabel di atas, jumlah rata-rata skor ruang lingkup audit syariah di Indonesia adalah untuk responden DPS/internal auditor sebesar 3,79; rata-rata skor responden eksternal auditor sebesar 3,32 dan rata-rata skor responden mahasiswa/i akuntansi syariah sebesar 3,35 dengan total rata-rata skor seluruh reponden sebesar 3,49. Dalam pengklasifikasian melalui garis kontinum jumlah total rata-rata skor seluruh reponden termasuk dalam kategori sesuai. Merujuk pada pengklasifikasian tersebut, maka dapat diartikan bahwa tanggapan responden tentang ruang lingkup audit syariah di Indonesia sesuai dengan harapan. 
Hal ini tidak sejalan dengan hasil temuan penelitian terdahulu yang dilakukan oleh (Kasim, Sanusi, Mutamimah, \& Handoyo, 2013) yang menemukan bahwa, bukan hanya kerangka kerja audit syariah saja yang masih mencari pedoman yang tepat, tetapi begitu pula dengan ruang lingkup audit syariah di Indonesia masih belum dilaksanakan sesuai dengan harapan, yakni lebih luas dari audit konvenional. Dalam penelitian itu juga diterangkan bahwa saat dilakukan interview, mayoritas responden sepakat bahwa lingkup audit syariah harus lebih luas dari sekedar hanya melakukan pemeriksaan pada kepatuhan syariah (shariah compliance) produk LKS saja.

Terkait hal tersebut saat ini, lingkup pemeriksaan audit syariah di Indonesia baru mencakup dua hal yaitu, pemeriksaan audit pada laporan keuangan (termasuk Islamic Social Report dan CSR) dilakukan oleh auditor internal maupun eksternal dan pemeriksaan kepatuhan syariah produk LKS yang dilakukan oleh DPS. Diluar kedua aspek tersebut belum jelas apakah sudah dicakup dalam pemeriksaan DPS atau belum. Mengingat DPS belum memiliki pedoman pemeriksaan yang jelas, sehingga bisa saja DPS yang satu telah melakukan pemeriksaan di luar aspek kepatuhan syariah produk LKS sedangkan yang lain belum.

Didasarkan pada penjelasan di atas mengindikasikan audit syariah yang berjalan mayoritas cakupannya adalah perihal kesesuaian laporan keuangan dengan standar yang berlaku serta kesyariahan produk.

Sedangkan yang menjadi penyebab utama responden berpendapat bahwa saat ini ruang lingkup audit syariah di Indonesia telah mencakup aspek yang lebih luas dan telah sesuai harapan, sebagaimana yang dijelaskan (Kasim, Ibrahim, Hameed, \& Sulaiman, 2009) bahwa lingkup audit syariah harus lebih luas dari audit konvensional, didasarkan pada peraturan bank Indonesia Nomor 11/ 3 /Pbi/2009 tentang bank umum syariah, dijelaskan DPS bertugas dan bertanggung jawab mengawasi kegiatan Bank (LKS) agar sesuai dengan prinsip syariah. Yang diartikan bahwa DPS bertanggung jawab memeriksa semua aspek syariah LKS secara menyeluruh bukan hanya mengenai kepatuhan syariah pada produk saja, tetapi juga pada aspek opersional dan manajerial lembaga. Sehingga mulai dari produk, operasinal hingga majemen LKS dapat dipastikan kepatuhanya terhadap syariah.

Akan tetapi, dalam peraturan tersebut tidak dijelaskan secara spesifik apa saja yang perlu diawasi dan diperiksa oleh DPS untuk menjaga kepatuhan syariah LKS. Hal ini ditambah masih belum jelasnya kerangka kerja DPS untuk melakukan pemeriksaan kepatuhan syariah pada LKS, sehingga belum dapat dibuktikan sepenuhnya bahwa ruang lingkup audit LKS selain laporan keuangan dan kepatuhan syariah produk LKS telah termasuk lingkup yang dicakup dalam pemeriksaan audit syariah di Indonesia.

\section{Kualifikasi Auditor Syariah}

Pembeda audit syariah dan audit konvensional adalah aspek syariah yang menjadi landasan utama pelaksanaan audit syariah yang tidak diakomodir di dalam audit konvensional. Untuk itu pelaksana audit, auditor syariah membutuhkan dua kualifikasi, yaitu keuangan ataupun perbankan dan syariah. Bidang syariah yaang dimaksud disini adalah utamanya mengenai fiqih muamalah. Lebih baik lagi jika menguasi ilmu akuntansi ataupun auditing syariah karena lebih komprehensif bagi seorang auditor syariah, sebab baik aspek syariah maupun aspek keuangan dipelajari keduanya. Sehingga, auditor dapat langsung menguasai kedua kualifikasi tersebut. Untuk mengetahui pendapat responden kualifikasi auditor syariah ini, dapat dilihat melalui tabel berikut ini : 
Tabel 4. Hasil Jawaban Responden Mengenai Kualifikasi Auditor Syariah

\begin{tabular}{|c|c|c|c|c|c|c|c|c|c|c|}
\hline No & Item Pertanyaan & & \multicolumn{2}{|c|}{$\begin{array}{l}\text { DPS/Internal } \\
\text { Auditor }\end{array}$} & \multicolumn{2}{|c|}{$\begin{array}{l}\text { Eksternal } \\
\text { Auditor }\end{array}$} & \multicolumn{2}{|c|}{$\begin{array}{l}\text { Mahasiswa/i } \\
\text { Jurusan } \\
\text { Akuntansi } \\
\text { Syariah }\end{array}$} & \multicolumn{2}{|c|}{ Total } \\
\hline \multirow[t]{8}{*}{8} & \multirow{8}{*}{$\begin{array}{l}\text { Auditor syariah } \\
\text { harus memiliki } \\
\text { sertifikasi keahlian } \\
\text { audit syariah }\end{array}$} & & $\mathrm{F}$ & $\%$ & $\mathrm{~F}$ & $\%$ & $F$ & $\%$ & $\mathrm{~F}$ & $\%$ \\
\hline & & STS & 1 & 5,3 & $\mathrm{o}$ & 0,0 & $\mathrm{o}$ & 0,0 & 1 & 1,7 \\
\hline & & TS & o & 0,0 & o & 0,0 & 1 & 3,3 & 1 & 1,7 \\
\hline & & $\mathrm{N}$ & 5 & 26,3 & 3 & 27,3 & 4 & 13,3 & 12 & 20,0 \\
\hline & & $S$ & 9 & 47,4 & 7 & 63,6 & 15 & 50,0 & 31 & 51,7 \\
\hline & & SS & 4 & 21,1 & 1 & 9,1 & 10 & 33,3 & 15 & 25,0 \\
\hline & & Total & 19 & 100 & 11 & 100 & 30 & 100 & 60 & 100 \\
\hline & & Mean & \multicolumn{2}{|c|}{3,79} & \multicolumn{2}{|c|}{3,82} & \multicolumn{2}{|c|}{4,13} & \multicolumn{2}{|c|}{3,91} \\
\hline
\end{tabular}

Berdasarkan pada tabel tersebut, tanggapan responden mengenai keharusan seorang auditor syariah memiliki dua kualifikasi, baik dibidang syariah maupun keuangan yang dibuktikan melalui sertifikasi yaitu sertifikasi keahlian audit syariah diperoleh ratarata skor responden DPS/internal auditor sebesar 3,79; skor rata-rata eksternal auditor sebesar 3,82 dan skor rata-rata responden mahasiswa sebesar 4,13 dengan total rata-rata seluruh responden mencapai 3,91. Bila skor terendah 1 adalah tidak setuju dan 5 adalah sangat setuju, dengan total rata-rata skor seluruh responden adalah 3,91 maka tergolong dalam kategori setuju, maka hal ini mengindikasikan bahwa seluruh responden sepakat dan setuju bahwa hanya auditor yang memiliki sertifikasi tersebut yang boleh menjalakan fungsi audit syariah.

Hal ini sejalan dengan aturan yang berlaku, yakni berdasarkan ketentuan Surat Edaran Bank Indonesia Nomor 7/57/DPbS 22 sejak Desember 2005 dijelaskan, yang dapat mengaudit bank yang melaksanakan kegiatan usaha berdasarkan prinsip syariah, hanya Akuntan Publik yang memiliki sertifikat pendidikan atau pelatihan di bidang perbankan syariah. Hal ini berkaitan erat dengan kondisi tidak semua auditor memahami aspek syariah dari LKS yang merupakan aspek utama aktivitas bisnisnya. Begitu pula dengan DPS, berdasarkan Peraturan Bank Indonesia Nomor 11/ 3 /Pbi/2009 Tentang Bank Umum Syariah kompetensi minimum seorang DPS adalah paling tidak memiliki pengetahuan dan pengalaman di bidang syariah mu'amalah dan pengetahuan di bidang perbankan dan/atau keuangan secara umum.

Dengan demikian baik hasil tanggapan responden maupun aturan hukum yang berlaku di Indonesia sepakat bahwa auditor yang berhak melaksanakan audit syariah atau dikenal dengan istilah auditor syariah adalah auditor yang memiliki kompetensi dalam dua kualifikasi yaitu kualifikasi dalam bidang keuangan (akuntansi/audit/perbankan) dan syariah (fiqh muamalah terutama). Maka dari itu, sertifikasi di bidang audit syariah sangat lah diperlukan. Untuk saat ini, Indonesia sudah memiliki Sertifikasi Akuntan Syariah (SAS) meskipun belum ada sertifikasi khusus auditor syariah. Walaupun pemegang sertifikasi ini 
masih sangatlah minim, hingga tahun 2014 berdasarkan data yang dikeluarkan IAI jumlah auditor yang memiliki gelar SAS baru sebanyak 54 orang.

Hasil penelitian ini ternyata mendukung penelitian yang dilakukan oleh (Kasim, Ibrahim, Hameed, \& Sulaiman, 2009), bahwa seorang auditor syariah harus memiliki dua kualifikasi, yakni kualifikasi syariah (fiqh muamalah) maupun di bidang keuangan. Dalam penelitian lain yang dilakukan oleh (Kasim, Sanusi, Mutamimah, \& Handoyo, 2013) di Indonesia, diketahui bahwa terjadi lack pada aspek kualifikasi auditor syariah. Lack ini terjadi dikarenakan hingga saat ini di Indonesia, lembaga pendidikan yang mencetak akuntan syariah sangatlah minim yang berimbas pada praktisi auditor syariah yang terbatas.

Hal ini juga menjadi salah satu penyebab terbatasnya lingkup audit syariah saat ini karena minimnya praktisi auditor syariah yang mememiliki kualifikasi mumpuni untuk menjalankan pemerikasaan audit syariah secara komprehensif. Ditambah tidak semua DPS memahami mekanisme audit syariah, karena di Indonesia rata-rata perbandingan dua kualifikasi yang dimiliki DPS saat ini belum 50:50, rata-rata penguasaan ilmu syariah yang lebih tinggi. Dan belum maksimalnya peran internal auditor yag dapat bersinergi dengan DPS melalui internal syariah review belum dimiliki oleh mayoritas LKS. Meskinpun kini tiap LKS wajib memiliki direktur kepatuhan termasuk kepatuhan syariah (shariah compliance) yang seharusnya bisa mengakomodir kebutuhan ini. Aturan tersebut tertera dalamPBI No.11/33/PBI/2009 tanggal 7 Desember 2009 tentang Pelaksanaan GCG Bagi Bank Umum Syariah (BUS) dan Unit Usaha Syariah (UUS) antara lain mengatur pula bahwa BUS wajib memiliki 1 (satu) orang direktur yang bertugas untuk memastikan kepatuhan terhadap ketentuan Bank Indonesia dan peraturan perundang-undangan lainnya.

\section{Independensi Auditor Syariah}

Dalam menjalankan tugasnya seorang auditor tidak hanya dituntut memiliki kualifikasi dan keahlian yang memadai namun juga sikap independensi. Kepercayaan stakeholder pada auditor sangat bergantung pada hal ini. Untuk itu auditor harus harus independen secara sikap dan mental maupun kelembagaan. Berikut ini tanggap responden mengenai independensi pemeran kunci audit syariah di Indonesia yakni DPS, internal auditor dan eksternal auditor dapat dilihat melalui tabel berikut ini :

Tabel 5. Hasil Jawaban Responden Mengenai Independensi Key Player Audit Syariah

\begin{tabular}{|c|c|c|c|c|c|c|c|c|c|c|}
\hline \multirow[t]{2}{*}{ No } & \multirow[t]{2}{*}{ Item Pertanyaan } & & \multicolumn{2}{|c|}{$\begin{array}{c}\text { DPS/Internal } \\
\text { Auditor }\end{array}$} & \multicolumn{2}{|c|}{$\begin{array}{l}\text { Eksternal } \\
\text { Auditor }\end{array}$} & \multicolumn{2}{|c|}{$\begin{array}{l}\text { Mahasiswa/i } \\
\text { Jurusan } \\
\text { Akuntansi } \\
\text { Syariah }\end{array}$} & \multicolumn{2}{|c|}{ Total } \\
\hline & & & $\mathrm{F}$ & $\%$ & $\mathrm{~F}$ & $\%$ & $\mathrm{~F}$ & $\%$ & F & $\%$ \\
\hline \multirow[t]{5}{*}{9} & \multirow{5}{*}{$\begin{array}{l}\text { Auditor syariah (DPS, } \\
\text { internal auditor LKS, } \\
\text { eksternal auditor) saat } \\
\text { ini independen atas } \\
\text { organisasi atau lembaga } \\
\text { tempat mereka bekerja }\end{array}$} & STS & o & o & o & o & o & o & o & 0 \\
\hline & & TS & o & $\mathrm{o}$ & $\mathrm{O}$ & $\mathrm{o}$ & 7 & 23,3 & 7 & 11,7 \\
\hline & & $\mathrm{N}$ & 2 & 10,5 & 5 & 45,5 & 11 & 36,7 & 18 & 30 \\
\hline & & $S$ & 12 & 63,2 & 6 & 54,5 & 12 & 40,0 & 30 & 50 \\
\hline & & SS & 5 & 26,3 & o & o & o & o & 5 & 8,3 \\
\hline
\end{tabular}




\begin{tabular}{|c|c|c|c|c|c|c|c|c|c|}
\hline & Total & 19 & 100 & 11 & 100 & 30 & 100 & 60 & 100 \\
\hline & Mean & & & & & & & & 6 \\
\hline
\end{tabular}

Berdasarkan pada tabel tersebut, jumlah skor rata-rata tanggapan responden mengenai independensi key player audit syariah adalah untuk skor responden DPS/Internal Auditor sebesar 4,16; rata-rata skor responden eksternal auditor sebesar 3,55 dan rata-rata skor responden mahasiswa/i akuntansi syariah sebesar 3,17 dengan keseluruhan total skor ketiga kelompok responden sebesar 3,60. Apabila digambarkan dalam garis kontinum berikut, berdasarkan pada pengklasifikasian jumlah skor rata-rata tanggapan responden berada pada kategori independen. Artinya tanggapan responden mengenai independensi key player auditor di Indonesia adalah independen.

Berdasarkan pada tabel dan disesuaikan dengan garis kontinum, maka terlihat DPS/internal auditor dan eksternal sebagai key player audit syariah di Indonesia menganggap mereka independen baik secara mental maupun kelembagaan. Namun, apabila melihat tanggapan kelompok responden mahasiswa/i yang bukan merupakan key player dan tidak terlibat secara langsung dalam praktik audit syariah dan dinilai lebih objektif, menganggap bahwa independensi key player audit syariah di Indonesia hanya sampai pada kategori cukup independen dengan jumlah skor rata-rata tanggapan yang diperoleh sebesar 3,17. Artinya kelompok responden mahasiswa/i meanggap adanya aspek yang belum independen di antara ketiga key player tersebut.

Berdasarkan penelitian yang dilakukan oleh (Kasim, Ibrahim, Hameed, \& Sulaiman, 2009), dihasilkan temuan bahwasanya manfaat penuh dari audit syariah tidak dapat direalisasikan jika auditor dan DPS tidak sepenuhnya atau benar-benar independen. Terutama ancaman terbesar datang kepada DPS yang perlu untuk memiliki garis jelas mengenai pemisahan tugas DPS sebagai pelaksana fatwa dan juga pelaksana audit syariah.

Realita tersebut juga terjadi di Indonesia DPS yang merupakan pemeran utama dari praktik audit syariah, berada di dalam LKS dan digaji oleh tempat mereka bekerja mekasanakan tugas dan wewenangnya. Arti sederhananya DPS mengaudit hasil pekerjaan mereka sendiri, akibatnya munculah isu-isu independensi seperti isu konflik kepentingan. Selain itu, hasil pendapat yang dikeluarkan oleh DPS tidak dilakukan pengecekan kembali oleh auditor eksternal atau akuntan publik sebagaimana laporan keuangan yang dikeluarkan manajemen sehingga terjadi check and balance terhadap hasil laporan tersebut yang membuatnya semakin terpercaya. Hal ini juga sejalan dengan penelitian (Kasim, Sanusi, Mutamimah, \& Handoyo, 2013) di Indonesia, yang menghasilkan temuan bahwa selain ketiga isu yang dijelaskan sebelumnya mengalami lack dalam praktik audit syariah di Indonesia ternyata independensi juga mengalami hal yang sama. Artinya penelitian ini bertolak belakang dengan hasil penelitian terdahulu dan kondisi yang terjadi.

Hal ini disebabkan responden sendiri adalah pelaku dan pemeran kunci praktik audit syariah di Indonesia, yaitu DPS/internal auditor dan eksternal auditor sehingga jelas memandang bahwa mereka telah independen. Tetapi hal ini bukan tanpa sebab, DPS berpendapat bahwa mereka independen mengacu pada posisi mereka didalam lembaga yang sejajar dengan direksi dan tidak terlibat aktivitas operasi serta berada di atas manajemen. Sedangkan internal auditor berada di bawah komite audit dan bertanggung jawab langsung pada direktur. Dan eksternal auditor merasa independen karena posisinya di luar lembaga dan bertanggung jawab langsung pada semua stakeholder serta masyarakat serta harus menjaga nama baik kantor akuntan publiknya agar tetap terpercaya.

Terlepas dari hal tersebut, isu-isu mengenai independensi memang selalu mengiring keberadaan sebuah fungsi pengawasan. Bahkan pada Akuntan Publik (AP) sekalipun resiko akan hal ini mungkin terjadi, seperti apa yang terjadi pada kasus fraud Enron. Inc dan KAP 
Andersen yang sangat merusak citra auditor. Apa lagi internal auditor yang memang fungsi utamanya adalah pengawas internal lembaga yang membantu manajemen untuk mendorong efektifitas dan efisiensi perusahaan. Untuk itu, hal yang paling penting adalah kesadaran auditor syariah (DPS, Internal/Eksternal Auditor) bahwasanya pengawasan paling utama adalah Allah SWT dan tujuan utamanya adalah meraih kebahagiaan dunia dan akhirat serta bekerja untuk kemaslahatan umat.

\section{SIMPULAN}

Mengacu pada hasil pembahasan diketahui bahwa mayoritas responden menganggap bahwa praktik audit pada LKS telah berjalan dengan cukup sesuai. Hal ini tergambar dari keseluruhan jumlah total rata-rata tiga kelompok responden terhadap 9 pernyataan untuk 4 indikator tersebut termasuk dalam kategori baik. Untuk pernyataan kerangka kerja audit syaariah diperoleh jumlah rata- rata skor responden dari 6o responden sebesar 3,29 yang berdasarkan pada pengklasifikasian tergolong pada kategori cukup sesuai. Untuk pernyataan ruang lingkup audit syariah diperoleh jumlah rata-rata skor responden sebesar 3,49 dan tergolong pada kategori sesuai. Untuk jumlah skor rata-rata seluruh responden mengenai kualifikasi yang harus dimiliki auditor syariah diperoleh angka sebesar 3,91 yang artinya mayoritas responden sepakat bahwa auditor syariah perlu memiliki dua kualifikasi dibuktikan melalui kepemilikan sertifikasi keahlian di bidang auditing syariah/akuntansi syariah. Dan terakhir terkait independensi diperoleh hasil skor rata-rata dari seluruh respondensebesar 3,6 yang artinya mayoritas reponden menganggap bahwa key player audit syariah di Indonesia, yaitu DPS,internal auditor, eksternal auditor telah independen dari tempat mereka bekerja.

\section{PUSTAKA ACUAN}

Abdul-Razzaq, A. A. (2009). Sharia Supervision as a Challenge for Islamic Banking in Nigeria. Oloyede I.O. (ed.), Al-Adl (The Just): Essays on Islam, Islamic Law and Jurisprudence .

Bank Indonesia dan Institut Pertanian Bogor. (2004). Potensi, Preferensi dan Perilaku Masyarakat terhadap Bank Syariah di Wilayah Kalimantan Selatan. Jakarta: Bank Indonesia.

Harahap, D. S. (2002). “Auditing Dalam Prespektif Islam” . Jakarta: PT. Pustaka Quantum.

IAI. (2013). Pemegang SAS. Retrieved 03 23, 2014, from Sertifikasi Ikatan Akuntan Indonesia (Sertifikasi IAI): http://iaisertifikasi.blogspot.com/p/pemegang-cpsak.html?view=snapshot

Ibrahim, S. H. (2008). The case for Islamic auditing. International Accountant , 21-25.

Imran, M. S., Ahmad, A., \& Bhuiyan, M. Z. (2012). Auditing in Islamic Perspective and Auditing as Practiced in some selected Islamic Banks Operating in Bangladesh. IIUC STUDIES , 9, 293-306.

Junusi, R. E. (2012). Implementasi Syariah Governance Serta Implikasinya Terhadap Reputasi dan Kepercayaan Bank Syariah. Annual International Conference on Islamic Studies (AICIS), (pp. 1828-1848). Surabaya.

Karim, R. A. (1990). The Independence of Religious and External Auditor: The Case of Islamic Banks. AAAJ , 3 (3), 34-44.

Kasim, N. (2010). Auditing from the Islamic Perspective. Accountants Today, pp. 28-31.

Kasim, N., \& Sanusi, Z. M. (2013). Emerging issues for auditing in Islamic Financial Institutions:. Empirical evidence from Malaysia , 8 (5), 10-17. 
Kasim, N., Ibrahim, M., Hameed, S., \& Sulaiman, M. (2009). Shariah auditing in Islamic financial institutions: exploring the gap between the" desirable" and the" actual". Global Economy \& finance journal, 2(2) , 127-137.

Kasim, N., Sanusi, Z. M., Mutamimah, T., \& Handoyo, a. S. (2013). Assessing the current practice of Auditing in Islamic Financial Institutions in Malaysia and Indonesia. International Journal of Trade, Economics and Finance, Vol. 4, No. 6, December .

Khan, M. A. (1985). Roles of the Auditor in an Islamic Economy. J. Res. Islamic Econ , 3 (1), 31-42.

Lewis, M. K., \& Algoud, L. M. (2007). Perbankan Syariah. PT. Serambi Ilmu Semesta.

Mardian, S. (2015). Tingkat Kepatuhan Syariah di Lembaga Keuangan Syariah. Jurnal Akuntansi dan Keuangan Islam , 3 (1), 56 - 67.

Rahman, A. R. (2008). Shariah Audit for Islamic Financial Services: The Needs and Challenges. ISRA Islamic Finance Seminar (IIFS) (pp. 1-14). Kuala Lumpur: ISRA.

Shafeek, F. (2013). Exploring Undergraduate Students' Understanding of Shari'ah Based Audit: Implications for the Future of Shari'ah Auditing Labor Market in Brunei. Asian Journal of Finance \& Accounting, Vol. 5, No. 2 .

Sultan, S. A. (2007). A Mini Guide to Shari'ah Audit for Islamic Financial Institutions-A Primer. CERT Publications Sdn Bhd.

Wardayati, S. M. (2011). Implikasi Shariah Governance Terhadap Reputasi dan Kepercayaan. Walisongo, Volume 19

Yaacob, H. (2012). Issues and Challeges of Shariah Audit in Islamic Finance Institution: A Contemporary View. 3rd International Conference On Business And Economic Research (3rd ICBER 2012) Proceeeding. Bandung.

Yaacob, H., \& Donglah, N. K. (2012). Shari'ah Audit in Islamic Financial Institutions: The Postgraduates' Perspective. International Journal of Economics and Finance; Vol. 4, No. 12 . 